\section{THE CAVITÉ DRYDOCK}

BY DAY ALLEN WILLEY.

The tests of the floating drydock designed by the United States government for service in the Philippines have proved so successful, that the craft is now on its way to Cavité.

Since its completion it has been lying in Chesapeake Bay off Solomon's Island. Here an opportunity has been given to thoroughly demonstrate its capacity for docking not only vessels, but to dock itself. In each trial the drydock has performed service up to the requirements of the specifications. The vessels selected for the tests were the new cruiser "Colorado" and the battleship "Iowa." The reason for docking a ship of each class was to determine the strength of the dock by different distributions of weight upon it. It may be needless to say that the "Colorado" is considerably longer than any of the battleship class, being more than 500 feet.

Consequently, the weight of the "Colorado," though much more, was distributed over such a greater length of the dock that the strain upon it as indicated by the deflection was considerably less than when the battleship was lifted from the water; but as already stated, the deflection was no more than the calculations of the the dock forty-eight hours. During this trial the total deflection of the keel line at the time when the "Iowa" had attained the greatest freeboard was two inches. At the end of twenty-four hours the deflection had increased to four inches, but strange to say at the end of forty-eight hours the dock had actually straightened until the deflection was but $3 \%$ inches. After the ship had again entered the water, an examination of the keel line showed a "hog" or bulge measuring about an inch, which in twelve hours had changed to the sag of about a half inch.

The most interesting of the tests by far, however was the docking of the center section of the structure by utilizing the pontoons at either end. To clearly explain how this remarkable engineering feat was made practicable, a brief explanation of the adjustment of the pontoons should be given. As readers of the ScICrTiric Avrrican are aware, the main pontoon is no less than 316 is 170 feet over all. The ends of the main overhang the smaller ones, each of the latter having an outside independent side wall high enough to allow it to be sunk and hauled under the center structure, literally fitting around the center on the same principle as the familiar collapse or telescopic box. When the latter were filled until it had sunk to the proper depth. The end pontoons were then turned so that the direction of the length of each was perpendicular to the axis, which allowed them to be floated over the main portion and centered on keel blocking, the plan followed being similar to that in the docking of vessel. The center pontoon was then pumped out, and the ends lifted to the proper freeboard without difficulty.

In docking the cruiser the entire structure was sunk to the maximum depth in one hour and thirty-six minutes, but pumped out in less than this period, the exact time being one hour and two minutes. Considering the size of the "Colorado" and the magnitude of the work involved, the time required was remarkably short, as only two hours and sixteen minutes elapsed from the time the ship was landed on the blocks until the keel was raised completely out of water. The "Iowe" was lifted above the surface of nutes, and to the freeboard of $41 / 2$ feet in two hours and forty-two minutes, but during this operation one of the three pumping engines in the main pontoon ceased working for forty-two minutes, so that with the entire pumping capacity of the dock in operation, the time would have

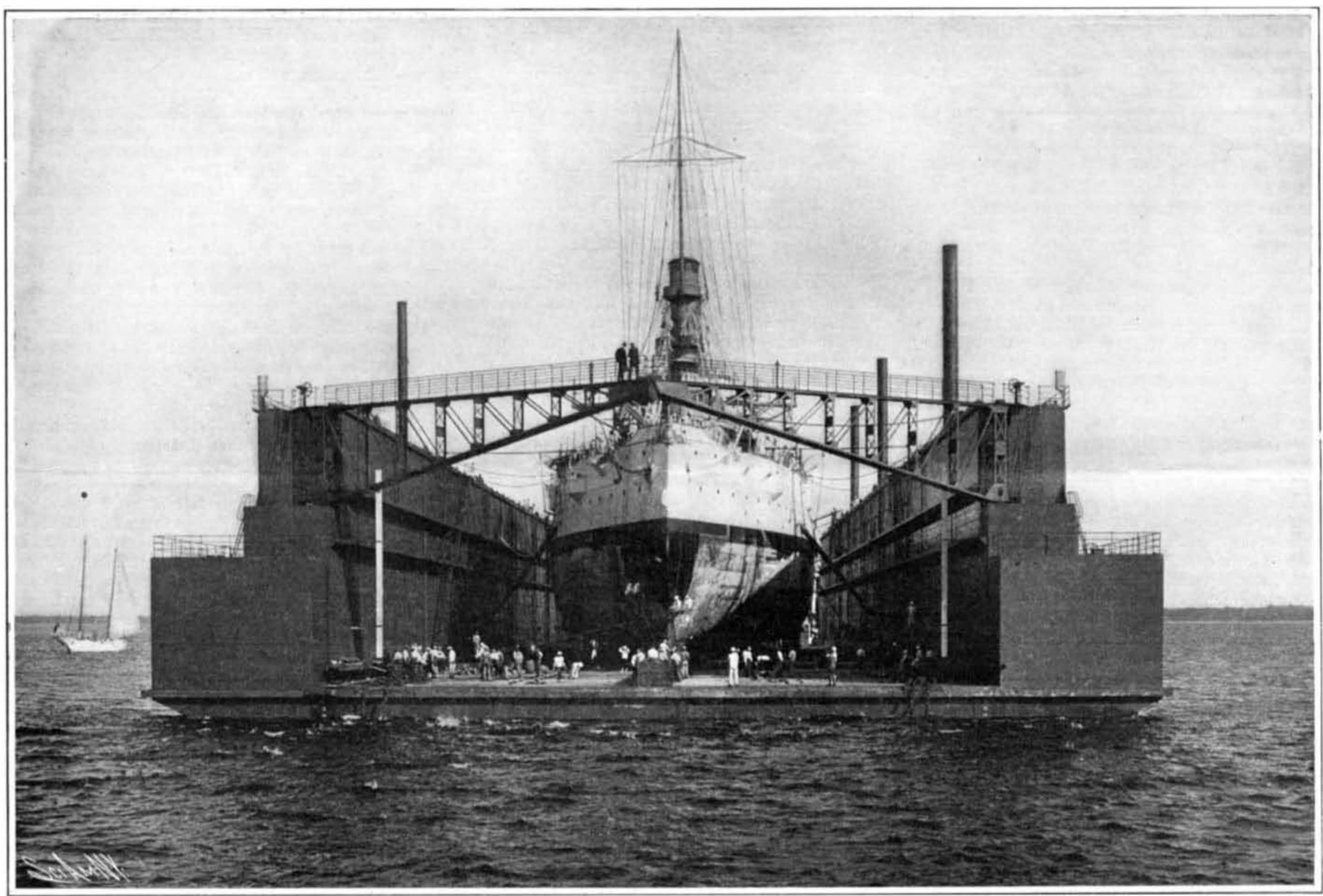

Water Completely Pumped Out of the Dock and the Vessel Raised THE CAVITÉ DRYDOCK

engineers-in fact, was not as great as that for which allowance had been made.

At the time she was placed in the dock the "Colorado" represented 13,300 tons displacement. In allowing the ship to enter the dock the latter was sunk to a draft of 29 feet over the keel blocks. The cruise was then placed in position, the pumping machinery set in motion, and the dock lifted until a freeboard was provided of $21 / 2$ ' feet. In this position the ship was carried during a period of twenty-four hours, measurements being raken from time to time to ascertain the exact effect of the weight upon the dock structure. When the greatest freeboard had been at tained, the total deflection upon the 500 feet of kee line of the dock supporting the vessel was found to be but one-quarter of an inch. At the end of twenty-four hours the total deflection was 11-16 inches., But after the ship had left the dock, the keel line straightened until no deflection was apparent.

While the "Iowa" represented but 11,600 tons displacement, the docking of this ship was probably a more severe test, not only by reason of the weigh resting upon merely a portion of the dock, but on account of the length of time the ship was held in position and the height of the freeboard. The latter was no less ihan $4 \frac{1}{2}$ feet, while the battleship remained in the three sections of the dock are connected and in service, the connecting elements consist of 2-inch bolts arranged in series, each series consisting of 44 . These bolts are adjusted so that they can be readily re maved, but as the tests demonstrated, rigidly hold the three sections of the structure.

To perform the first operation of self-docking, all portions of the center pontoon under water were required to be raised to a height of not less than five feet above the surface-thus allowing sufficient space to scrape and paint the bottom when deemed necessary. In raising the center pontoon, the connecting bolts were first removed between it and the ends. The latter were then submerged to such a depth as to allow twelve inches of clear. space between their ship deck and the bottom of the center pontoon. This permitted them to be drawn under it and "centered" As the main section had been pumped out before the ends were placed on it, the only work remaining was to remove the water in the end compartments to the proper draft, thus lifting the weight.

The dock was also designed not only to lift the center pontoon from the water, but the ends. In this operation the movements were practically reversed. The eration the movement connecting bolts being removed, the end pontoons were first hauled clear of the center. The compartments of been somewhat shorter. In the self-docking tests each pontoon was sunk, hauled out, pumped to the proper draft, and connections made in twelve hours. In brief, the decision of the board of supervising engineers was that the dock is of sufficient strength and capacity to dock a ship of 20,000 tons displacement.

The arrangements for towing this great structure are of no little interest, on account of the length of the voyage and the weight and dimensions of the dock. While the framework, plating, and machinery contained represent a weight of nearly 11,000 tons, its height above the water, its unwieldy proportions, as well as draft make it far more difficult to tow in a seaway than an ordinary craft. In fact, it is a question if a raft cannot be guided with less difficulty. The towing fleet selected is composed of three United States colliers. The largest of these is the "Glacier," a ship of 7,000 tons displacement and having engines of 5,000 horse-power. The "Glacier" will be assisted by the "Caesar," of 5,016 tons displacement, having engines of 1,500 horse-power, and the "Brutus," of 6,000 tons and 1,250 horse-power. Consequently, the entire towing power will aggregate nearly 8,000 horseyower. The smaller craft, however, will be used not only for direct towing, but for steadying the dock in rough weather. In case of a storm, the suggestion 
has been made that it can be sunk to its maximum depth, thus exposing but a small portion of its side walls to the sea. The engineers, however, are of the opinion that its construction is sufficiently heavy to withstand a very severe strain

The route selected is by way of the Suez Canal. While this is somewhat shorter than around the Cape of Good Hope, it is calculated that the dock will cover nearly 11,000 miles before reaching its destination.

\section{Interesting Facts Concerning the Carpet Industry}

Some interesting facts concerning the carpet industry of Persia are contained in the latest report of the British consul general for that country. Carpet manufacturing at Khorassan and the majority of the other manufacturing centers is divided into two classestown woven and nomad woven. In Meshed itself there are 400 frames; in the Turshiz district there are over in which to dispose of their stocks of carpets condemned by this measure.

\section{Why Do We smell ?}

Is the sense of smell excited by gases or particles? According to Dr. John Aitken, F. R. S., the eminent English specialist, who has devoted considerable time

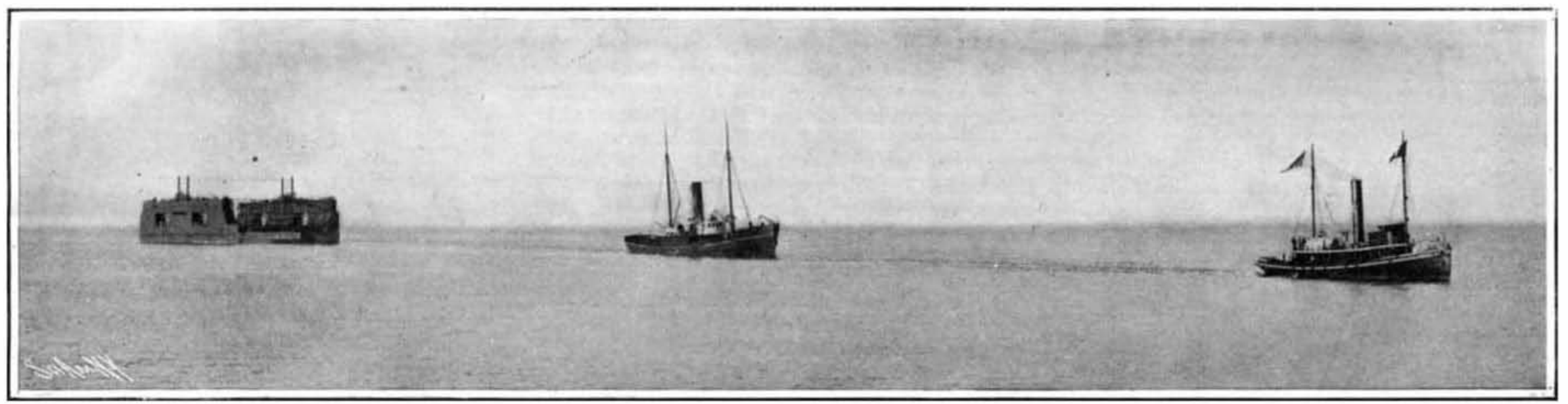

Towing the Algiers Dock to Its Station on the Mississippi, Showing How the Cavite Dock Will be Taken to the Philippines.

By the ordinary sailing route the distance is 11,650 miles, going by way of the Straits of Gibraltar, the Mediterranean Sea, the Canal, the Indian Ocean, the Straits of Malacsa and the China Sea, although it may be necessary to take the dock to the south of Sumatra Island and not through the Straits. The question of towing through the Suez Canal is no small problem, for the minimum width which will accommoll problem structure is 200 feet, the width of the dock itself being 134 feet. Therefore but 66 feet leeway is allowed to work it through the narrowest part of the canal. The Navy Department calculates that the fleet can move at the rate of about 100 miles per day, allowing about four months for the entire voyage. In towing, the cables used will be attached to machines which automatically pay out and haul in the connecting lines, thus easing off the great strain, which would probably break the cables in a heavy sea.
50 frames, and further south near Duruksh, in the Kain district, over 450 looms were found working. None of these carpets can vie with the exquisite products of Kerman, although the quality and color are improving. There are from 2,000 to 3,000 looms in which nomad carpets are woven. These Baluch carpets are mainly worked in dark shades of red and blue. An interesting custom prevails among the nomad tribes by which a girl, before becoming eligible for marriage, has to prove her skill by weaving two very fine rugs or saddle-bags. It is this class of work which is particularly prized in Europe and America. In 1903-4 a law was re-enacted by the Persian government by which the customs department was instructed to seize and burn all carpets in the manufacture of which aniline dyes were used. A total cessation of exports resulted, and owing to the hardships inflicted by this decre manufacturers were granted a certain period of grace investigated musk, of which it is possible to detect by smell, according to Berthelot, $0.000,000,000,000,000,0$ gramme. Dr. Aitken carried out his researches upo the cloudy condensation basis, in which, if odors are attributable to particles, the latter form nuclei of cloudy condensation in supersaturated air, and thus make their presence visible. In the case of musk no such nuclei were detected, proving conclusively that musk does not give off solid particles, but evaporates as a gas or vapor, and that it is gaseous particle from the musk that act on the sense of smell. O twenty-three other odorous substances, not one gave its perfume in solid particles, nothing but gases or that our nostrils appear to substantiate this theory. The perfume of snuff, for Instance, is a soft, velvety sensation, while the effect of the solid is sharp and biting, more allied to pain than pleasure.

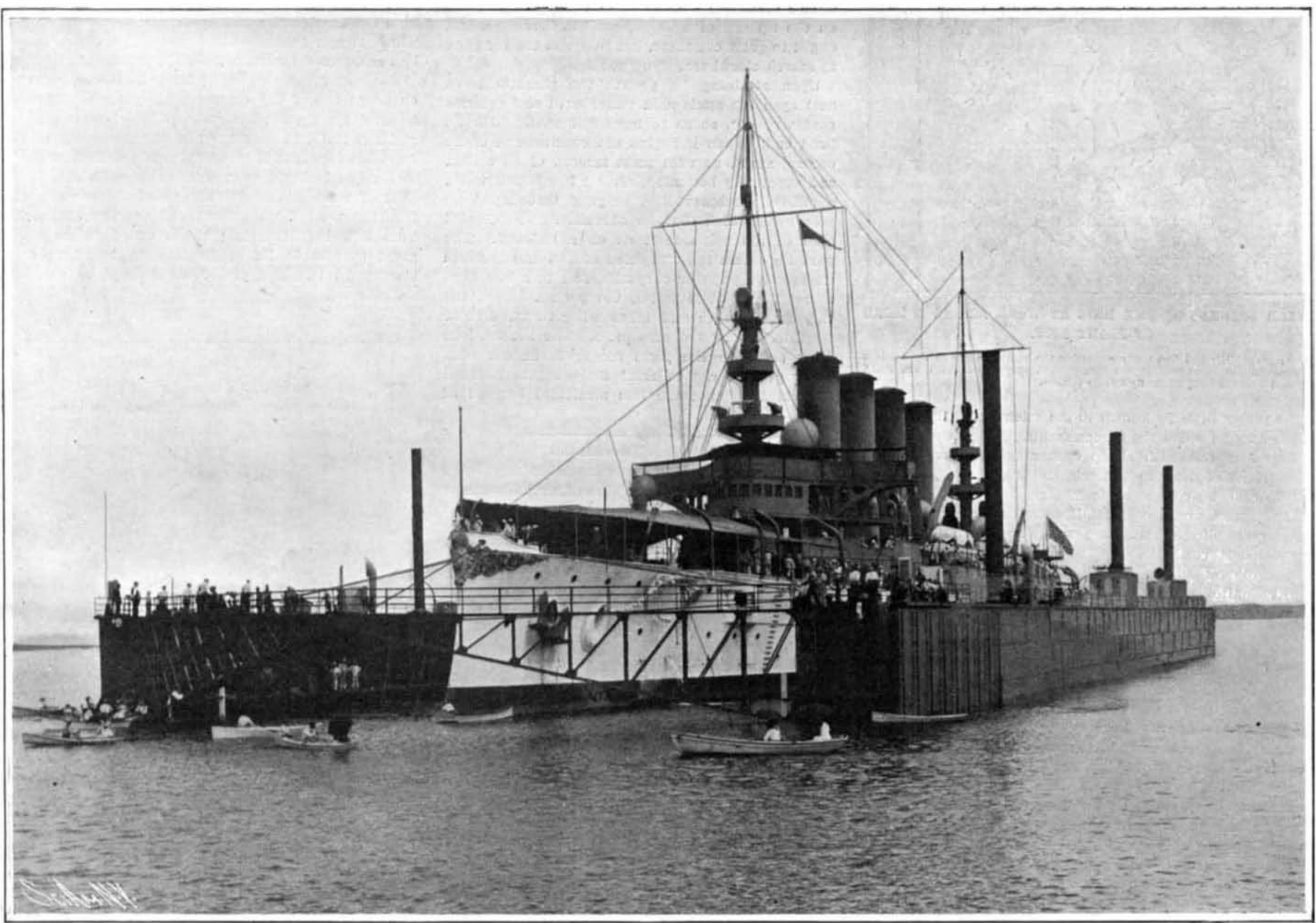

An Armored Cruiser Ready to be Lifted Ont of Water. 